\title{
A LITERATURE REVIEW OF HOUSEHOLD-LEVEL RISK FACTORS FOR DIARRHEA AND UPPER RESPIRATORY INFECTION IN INDONESIA
}

\author{
Tities Puspita1), Aparna Lal') \\ ${ }^{1)}$ Center for Health Research and Development of Public Health Effort, \\ National Institute of Health Research and Development, Jakarta, Indonesia \\ ${ }^{2)}$ School of Population Health Research, The Australian National University, \\ Canberra, Australia
}

\begin{abstract}
Background: Globally, diarrhea and respiratory infection are major causes of morbidity and mortality, especially in the under-fives. Household physical environment is a known risk factor for both diseases. However, a review of the published literature reporting this link in Indonesia is limited. This study aimed to synthesize and review evidences related to household physical environmental risk factors for diarrhea and upper respiratory infection in Indonesia.

Subjects and Methods: Literature in English and in Indonesian was collected from PubMed and Google Scholar. The searching inclusion criteria had been set to yield articles from five nationally accredited and peer-reviewed health journals by the National Institute for Health Research and Development, the Indonesian Ministry of Health. Specific search terms were used without date restrictions during the literature search in 2017.

Results: The final review included eleven journal articles from 1994 to 2016 with cohort, case-control, and cross-sectional designs. The national survey data were analyzed in the majority of the studies. Bivariate and/or multivariate were the method of analysis. Seven studies reported the relationship of household physical characteristics with diarrhea, sanitation, in-house density, and drinking water-related factors. Four articles discussed the associations of indoor air pollution, animal corral, floor type, and the unhealthy indoor environment with an upper respiratory infection.

Conclusions: Risk factors for diarrhea are sanitation, housing density and factors related to drinking water. Risk factors for upper respiratory tract infection are indoor air pollution, animal cages, type of floor and unhealthy indoor environment.
\end{abstract}

Keywords: household, diarrhea, respiratory infection, physical environment, Indonesia

\section{Correspondence:}

Tities Puspita. Centre of Health Research and Development for Public Health Efforts, National Institute of Health Research and Development, Jakarta, Indonesia. Email: tiespuspita@gmail.com. Mobile: +6281283774865. 